consequently in all the cases it was the right kidney which was exercising pressure. In all the enlarged or displaced kidrey was only found as the patients recovered. In Cases 1 and 3 the right kidney was found to be absent from the right loin, in Case 2 this was doubtful, in Case 4 the patient was too stout for this point to be ascertained. I cannot learn from such authorities as I have consulted, either on intestinal obstruction or displaced kidney, that this connexion which I sugsest is generally taught. If it be as suggested, one would judge that the cases, in which this causation of obstruction of the intestine of this kind exists, should be tolerably frequent, considering the frequency of displaced kidneys, and the number of women who suffer from that affection and habitual constipation. The fact of the right kidney being twelve or thirteen times more frequently displaced than the left and the fact that the ascending colon and hepatic flexure are common seats for blocking of the bowel with fæcal matter would point to the likelibood of this form of obstruction being more common on the right than the left side of the abdomen. This is borne out by the four cases which follow.

CASE 1.-A widow aged sixty-two. Her general health was good, with the exception of her being subject to constipation. Increasing difticulty of action of the bowels was followed by a sudden attack of very acute abdominal pain, obstinate vomiting, and pyrexia. On examination a tender indefinite mass was found in the right bypochondriac region, extending to the umbilicus. There was no hernia or jaundice, or other sign or history of biliary colic. The pain was relieved with difficulty even with full doses of morphia hypodermically. By means of enemata and calomel the bowels were relieved and old-looking fæcal matter removed. In the course of a week the pain, pyrexia, and vomiting were subdued, and a soft irregular mass was still felt on the right side, pitting on deep pressure. This disappeared after many months of careful regulation of the bowels by dieting and aperients. As the original mass was removed a displaced right kidney, fairly movable, was found to occupy the position of the facal tumour. The latter has long since disappeared and the kidney remains as before. The patient is now well, five years after the attack.

CASE 2.-A married woman forty-three years of age. The patient's general health was good except for hepatic functional disorder and constipation ; the latter had increased of late. She was seized with acute abdominal pain, pyrexia, and vomiting, symptoms similar to those of Case 1, but less severe. A tender mass was felt in the right hypochondriac region, irregular and fairly soft. The symptoms were quickly subdued by morphia, starvation, and hot applications, followed by frequent doses of cascara. Slowly the mass became smaller, pitting on deep pressure, and was evidently a fæcal tumour. This was quite removed and, as the patient recovered, she was found to have a movable right kidney roccupying the position of the mass found at the commencement of the illness.

(ASE 3.- This patient (a female) was forty-two years of age. She had been subject to "bilious attacks" for a few years, characterised by pain and vomiting, and followed by "diarrhœa," at uncertain intervals. When seen she was suffering from acute abdominal pain, distension, pyrexia, and vomiting, which became for a short time fæcal. These symptoms slowly subsided by means of similar treatment to that employed in the other cases, opiates, starvation, and enemata, followed by frequent doses of cascara and decoction of aloes. A mass was found occupying the right hypochondrium and the situation of the transverse colon, lying across the abdomen; it was very tender and pitted on pressure at the upper border. This patient recovered eventually after three or four weeks of somewhat severe illness. Considerable diminution in the mass was observed and the outline became defined, pitting on pressure ceased, and the swelling became more smooth and hard. This was evidently an enlarged and displaced right kidney, only slightly movable, forming part of the original mass. This remains as before after two years; the patient is somewhat delicate and takes aperients regularly. She is now able to follow her usual employment.

CASE 4. - A single woman serenty-two years of age. The patient has been subject for some years to slight attacks of abdominal pain, chiefly in the region of the transverse colon, with or without sickness, and followed by loose actions of the bowels. She was seized with sharp abdominal pain above the umbilicus, vomiting, distension of abdomen, and slight pyrexia. An irregular mass was found in the right hypochondrium; it was tender and pitted on deep pressure. The attack was soon relieved by opiates, starvation, and enemata. Large fæcal masses were removed and the original swelling became daily smaller and less tender and the outline more defined and smoother. It was then found to be a nearly fixed, displaced kidney, somewhat enlarged. This remains and the patient keeps herself in health by taking aperients regularly and by very careful dieting.

Montpelier-row, Blackheath.

\section{DESTRUCTIVE ULCERATION OF THE VAGINA.}

BY JAMES BRAITHWAITE, M.D.LOND.,

OBSTETRIC PHYSICIAN AND SURGEOY TO TAE LEEDS GENERAI INFIRMARY.

The various lapoid forms of alceration of the vulva, although not thoroughly worked out as regards the peculiar microbe which no doubt causes them, are nevertheless well known, and have been fully described, especially by the late Dr. Matthews Duncan. The same writer also wrote upon small patches and ulcers of the valva with tendency to hæmorrhage. Vlcerations confined to the vagina have received less attention, although cases occur of great importance. Two forms of extensive vlceration of the vagina have come under my notice. Both of them are most intractable in their nature and almost unamenable to any treatment, except improvement of the general health. The first form is, so far as I have seen, confined to the lower part of the vagina, the mucors membrane of which it destroys completely on its posterior surface. The second form is confined to the upper part or roof of the vagina, and is more superficial, but very chromic. Neither of them is malignant-i.e., cancerous. I can find no account of either of these diseases. They have no connexion with corroding ulcer or with any of the so-called lupoid forms of disease, as they are both unattended with any up-growth or hypertrophy. Of the first form I have only seen two cases, but as both were almost precisely alize I will, for facility of description, call it a form or species of disease. I can best describe it by giving a case.

CASE 1. - A woman aged fifty-fire, when in church, felt a slight draught of cold air in the face. This originated an inflammation of one eye, ending in its disorganisation, and it was removed by Mr. Secker Walker in the spring or summer of 1892. In August of the same year she came to me with complaint of uneasiness about the vagina, and I found an extensive and slowly spreading wiceration. This gradually extended almost round the whole lower part of the vagina. At first it consisted of four or five narrow whers occupying the bottom of the folds of the swollen and red mucous surface. The lower edge of each of these reached exactly to the lower margin of the true vagina, and they extended upwards to not guite half the length of the vagina on its posterior surface. These ulcers gradually coalesced, leaving, however, little tongues of undestroyed mucous membrane marking their original number. The edges were not excavated, but clear cut to the full depth of the ulceration. The moous membrane appeare to be entirely destroyed and the tisswes beneath laid bare. The surface was dry in appearance, the shight semi-purvilent secretion upon it being hardly visible except by close in spection. The colour was a deep bloish-red. There was no slough and the disease progressed by a slow molecular necrosis. It was not painful unless the parts were stretched for the parpose of examination. There was not the least thickening of the edges of the ulceration or any up-growt whatever, either in the surface or in any neighbourine part. Having thus destroyed the lower half of the vagina except the anterior fall, the disease then remained perfectly stationary for about four months. No local treatment ha any effect upon it, but lightly packing the part with lint steeped in a weak carbolic and zinc lotion, seemed to answe best. Both nitric acid and nitrate of silver were cautiously tried at spots on the edge, but they produced no tendency to heal. Meanwhile the patient was taking quinine, wine and as generous a diet as she could digest. Six month before she came ander my care she had had, as stated 
one eye extirpated for hopeless inflammation of a low type. She now began to show symptoms in the remaining eye which made me feel that some radical change mast be made or this eye would follow the fate of the other one. I insisted apon her leaving the town altogether, which she did in a few days, being thoroughly alarmed about the other eye. In the country her general health improved at once, and after a considerable time the vaginal surface began to beal by a thin pellicle of epithelium creeping over the denuded surface, and when I last saw her about Christmas, 1893, it was as nearly as possible all healed. This woman lived for years in a cellar kitchen in the lowest part of the valley. Here water is always found at a depth of about twenty feet below the surface of the ground which consists of loose gravel. At this time the patient kept no servant, and she worked very hard in the performance of her household duties, as she had a large family. When I knew her she was living in a good part of the town and was comfortably off. But the mischief had been done, and I take it that the impairment of health from the causes named was the origin of both the destruction of the eye and of the vagina. It naturally occurred to both Mr. Walker and myself that syphilis was the cause of the disease, but there was no evidence of this whatever, and on the contrary an absence of anything to even cause suspicion of it. I have seen one other case of this disease in a patient in my ward in the Leeds Infirmary which occurred about the same time as the one related, and the ulceration or molecular death of the vaginal wall precisely resembled that in this case, but it was not so extensive. There were the same sharp convex borders to the ulceration at its lower margin, and it stopped short of the valvar mucous membrane exactly as in the case described. It, however, did not extend so far round the vagina, but we could not get it to heal, and the patient went out with it unhealed. The case was seen by Mr. Firth, the resident obstetric officer, and by many students.

I will now pass on to the other form of ulceration, which is of a milder type, but almost equally intractable to treatment. The vaginal wall is really a skin structure with papillæ covered with a layer of squamous epithelium. This latter, in mounting a section for the microscope, takes the dye differently, and is usually here and there separated from the papilla underneath by the manipulations of dyeing and mounting, which shows that the union is not very intimate. It seems to me, from examining sections of this milder form of ulceration, that the squamous epithelium disappears and the papillæ are eroded but no destroyed. The disease is not very common, although in the form known as senile chronic raginitis having a "mapped appearance," as Dr. Matthews Duncan describes it, is not unfrequently met with, but I take this to be a separate disease, and one not usually attended with ulceration. The form of ulceration I am describing attacks, as far as my experience goes, the vaginal roof and upper part of the vagina only, and is never visible below. It is hardly recognisable by the finger alone, as the surface is smooth and soft. By the speculum it is seen to be of a dull red colour, with imperfectly defined edges. The sensation this communicates to the finger is not at all like that peculiar to very superficial squamous epithelioma in an early stage. The epithelioma gives to the finger passed over it a slightly crisp, hard feel, whereas the ulceration in question is peculiarly soft, otherwise some rare cases of epithelioma of the vagina closely resemble it, spreading at the edges widely in every direction, but implicating merely a film of epithelium. The edge of the epithelioma is slightly raised and very sharp and defined; that of the ulceration is perfectly level and shades off into the healthy surface without any sharp boundary line.

CASE 2.-A woman sixty-two years of age was admitted into the Women and Children's Hospital twenty years ago (I was then the junior surgeon there) with a large patch of disease, such as described, covering the whole of the vaginal roof and the posterior lip of the uterus on its vaginal surface. I had not then had the experience I have had since, and took it to be malignant. After consultation with my two senior colleagues, who agreed with me, I cut away the whole vaginal roof and shaved off the surface of the posterior lip of the uterus to about half its depth, but without opening the peritoneum. The result was a gap which I could not bring together by sutures, but observed that the parts laid fairly close when not disturbed by the introduction of the finger. The wound healed well, and the patient went home apparently free from disease. I have not seen her since. I subsequently, by microscopic examination of the part removed, found that it was not malignant, but a superficial spreading ulceration destroying the epithelium and partly the papillæ. I still have the sections in good preservation. This was the first case I saw, and since then, from time to time, but very rarely, I have met with similar cases, but none so extensive. Occasionally there is tendency to hæmorrhage. On June 14th we had one of these cases amongst the infirmary out-patients, and it was shown to my class of students. I have, however, not noted any of these cases except the one related, and prefer therefore to relate one by an independent observer, Dr. H. Briggs of Liverpool, who has kindly contributed his notes of the case. Dr. Briggs mentioned the case at a recent meeting of the North of England Gynæcological Society. It somewhat differs from the cases $I$ have seen in being painful, and hæmorrhage is more common in smaller and tuberculous ulcers than in this form of disease.

On Oct. 3rd, 1893, Dr. Paton, of Rock Ferry, Cheshire, sent to me a widow aged fifty-one years, suffering from vaginitis. One of the symptoms was rather free hæmorrhage and the physical character of the ulceration was peculiar. The patient gave the following account of herself. She was the mother of twelve children and had had one miscarriage. Menstruation had been regular up to its cessation in the fiftieth year of her age. For twelve months there was not any vaginal discharge. She had not suffered from any pelvic complaint until this illness began two months ago (the aterus was in normal position and there was no cystocele). She had not worn a pessary or made any application to the vagina. There was no clear evidence of an exciting cause of the ulceration. At first the discharge was white and then whitish yellow; its quantity was considerable. A fortnight after the leucorrhcea appeared bleeding set in, and continued daily without intermission. The hæmorrhage was sometimes copions, and occasionally there were clots on the diaper. She was haunted with the fear of cancer, of which her husband had recently died. She was assured the disease was not cancerous. The bladder was irritable. Rest had little influence on the pain. After meals and during the night the pain and irritation were always worse. She was pale and thin; there was a distressed care-worn look-proof of how seriously the general health had suffered. On local examination by a Sim's speculum in situ irregularly shaped ulcers were seen which reached from the anterior lip of the cervix to the meatus urinarius; the ulcerated surfaces were not raised; the edges of the ulcers were thin and were correspondingly little raised above the surfaces of the ulcers. A dull, white, granular film thinly covered the surfaces of the ulcers. When the film was disturbed by a pledget of cotton-wool bleeding occurred. Contact of the finger produced the same result. The ulceration was superficial. The edges showed a pale dull-red congestion which faded gradually into the mucous membrane around. There was neither the bright redness of acute nor the lividity of chronic inflammation. She remained in the hospital for five weeks. The disease was limited to the upper vaginal wall throughout its whole course. Locally, with cleanliness and packing the vagina daily improvement set in. She was kept in bed. A liberal diet of plain food was given.

I can find no reference whatever to a disease such as has been described under the first so-called form of ulceration, and am inclined to think it is now for the first time described. The extensive but superficial form of ulceration differs also from anything described by Dr. Matthews Duncan or any other writer, but the case given by Dr. Briggs of Liverpool resembles them in the occarrence of hæmorrhage. I can give no absolute proof of it, but think there can be little doubt that both the forms of ulceration described are produced by cocci or bacteria, which would be powerless for mischief but for the feeble resistance of the tissues owing to poor general health from advancing, years and poverty with deficient nourishment. Possibly the microbes so acting are always present in the vagina in health, but are then harmless. The generative outlet or inlet of the body differs from the others in not having its surface scoured by friction, and injurious microbes are therefore allowed to remain at rest and take root. This is especially the case after the menopause, and the stagnant state of the secretions is not improbably a factor in the occurrence of such diseases as those described.

Clarendon-road, Leeds. 


\section{THE HYDERABAD CHLOROFORM COMMISSION :}

\section{A CRITICISM OF ITS METHODS AND RESULTS.}

BY J. FREDK. W. SILK, M.D. LOND.,

ANASTHETIST TO GUY'S AND KING'S COLLEGE HOSPITAIS, ETC.

UP to the present time, as far as I am aware, no opportunities have been afforded for criticising in public debate the methods and results of the Hyderabad Chloroform Commission from a general point of view. Such discussions as have hitherto been held have turned mainly upon the physiological aspect of the question, but as the issues involved are very great it is of no little importance that the matter should be discussed from every possible standpoint. A question which one is often asked is, Why was this commission appointed? The answer is to be found in Section 5 of the report as published in THE LANCET of Jan. 18th, 1890, in which we read: "The first commission was applied for by Surgeon-Major Edward Lawrie because, having always believed in the truth of Syme's teaching, he desired to show by experiments upon dogs that in death from chloroform the respirations always stop before the heart," and from a subsequent part of the same section I gather that the second commission was instituted to confirm by physiological experiments the results of the first. Surgeon-Major Lawrie was appointed president of the second commission. Practically, therefore, the main conclusions at which the commission arrived bad already been anticipated before any evidence had been brought before them, and it cannot be a matter of surprise to anyone that a commission appointed at the instigation of an individual holding certain definite views, and with that same individual as president, should produce a report consonant with those views, or even, as in this case, carrying those views a step or two further. Another question which one is often asked is, What was the constitution of the commission? In its final form the commission consisted of Surgeon-Major Lawrie (President), Dr. Lauder Brunton, Surgeon-Major Bomford, Mr. J. A. Kelly, Surgeon Hehir, Dr. Rustomji, and Mr. A. Chamarette. The commission as thus constituted is open to the very grave objection that, as far at any rate as I have been able to ascertain, not one of its members can claim to have had any recent or extended experience in the administration of chloroform elsewhere than in India, and it is, I believe, well known among Indian surgeons that the natives take chloroform remarkably well and that deaths, though not absolutely unknown, are very rare. For instance, Dr. Crawford, of the Madras General Hospital, says that the difference in mortality between India and Europe is not due to sureriority of method, but to absence of fear and vast difference in temperament. Habit, custom, and climate all tend to lessen the native's fear of losing consciousness. Snch being the origin and such being the constitution of the commission, it becomes more than usually imperative upon us to hesitate to accept their conclusions until the evidence has been carefully considered and confirmed by other observers. And what are the results arrived at by the commission? As far as I can make out they are as follows : (1) that in death from chloroform the respirations always stop before the heart; (2) that chloroform has no direct action upon the heart ; (3) that chloroform anæsthesia alone is free from risk ; and (4) that it is useless and dangerous to take the pulse as a guide to the effect of chloroform.

The evidence upon which these conclusions are arrived at is partly physiological, partly clinical. Not only has the physiological evidence received no direct confirmation, but such observers as the reconstituted Glasgow Committee, Professors Wood and Hare of Philadelphia, Professor McWilliam, Drs. Gaskell and Shore, and other eminent physiologists have expressed opinions which are the exact opposite to those of the commission. Surgeon-LieutenantColonel Lawrie has laid much stress upon the indirect confirmation afforded to the views of the commission by the apparent similarity between the Hyderabad tracings and those produced by Professor Victor Horsley in cases of gunshot wounds of the brain, but even Professor Horsley hesitates to go so far as to assert that in death from chloroform the respirations always stop before the heart or that chloroform has no direct action upon the heart, and it is obvious to everyone that we cannot decide such a print as this on the strength of curves produced under such entirely different conditions. But apart altogether from the interpretation of "curves" obtained in the physiological laboratory, it appears to me that these physiological experiments taken as a whole tend to prove how intimate are the relations between the cardio-vascular and the respiratory systems, and between the heart and rasomotorial functions. If all these elaborate precautions are necessary, even in the laboratory, to differentiate the effects of chloroform upon one system from those on the other, it must surely be next to impossible to do so on the operating table, and from this, I think, the most obvious deduction is that we should not confine our attention to any one particular function.

The clinical evidence upon which the commission relied appears to have been almost exclusively that furnished by Surgeon-Lieatenant-Colonel Lawrie in his statement that neither in the experience of Professor Syme nor in his own had a fatal case occurred for upwards of forty-three years. It is true that the report states that the commission had searched the records of fatal cases, but apparently only with the view of ascertaining whether or not the respirations had alone been watched, and as no such statement was definitely made in any individual case the searchers jump to the conclusion that these deaths only tend to establish their contentions! They have not, moreover, had any experience themselves in the matter, and cannot, therefore, give any positive evidence or views as to the cause of death in any one instance, but content themselves with rejecting the opinions and views of actual observers. With regard to Surgeon-Lieutenant-Colonel Lawrie's statement above alludec' to, I would point out, in the first place, that no actual figures are given and that no actual records appear such as could be fairly compared with the figures given by Dr. Julliard of Geneva, Dr. Ormsby of Dublin, the St. Bartholomew's Hospital statistics, the returns of the Registrar-General for England and Wales, and others. Professor Syme's experience, too, must be discounted a good deal because during his lifetime the number of operations was much fewer than at the present day and the number of administrations less both absolutely and relatively, and it follows therefore that an experience of twenty or thirty years in the time of Syme is not equivalent in point of numbers to a modern experience of much more than five or ten years. The same remark, too, applies to Surgeon-Lieutenant-Colonel Lawrie's seven years' English work, and with regard to his subsequent experience this, as I have already pointed out, is open to the exception that it is entirely Indian. In comparing figures on this point I think it is a matter of no little importance that there should be records of cases that die on the operating table or within a few minutes of being put back to bed, whether from "shock" or otherwise. I make this suggestion because there is a general impression that many of the deaths which in England are returned as being due to chloroform or other anæsthetic are, and in many instances rightly $\mathrm{I}$ think, recorded elsewhere as being due to shock. The records published at intervals during the last few years by Surgeon-Lieutenant-Colonel Lawrie, excellent. as they are in many ways, do not really help us much in this inquiry, inasmuch as they appear to ignore the existence of the circulation or the pulse altogether; we have just recently been promised from the same source a large number of records in which the omission referred to is rectified, and although it is impossible to criticise these records before they actually appear $I$ think it may be said that their value will be greatly enhanced if the pulse observations are taker by some perfectly impartial observer in no way connected with the commission nor a student of the Hyderabad school: better still would it be if the record could be made in some mechanical way, as by a recording drum.

So far from the views of the commission being confirmed clinically by others, we find on the other side of the shield the records of a host of observers-hospital surgeons, genera? practitioners, anæsthetists, and others - who agree in think ing that, in some instances at any rate, chloroform kills through the heart. For instance, without very carefully searching the records I find that in the year 1891 there are at least four cases reported in which it is most distirctly stated that, in the opinion of those actually present at the bedside, death seemed certainly due to syncope. I have chosen a year subsequent to the publication of the report because I think it may fairly be concluded that the observers were fully alive to the point in dispute-i.e., whether or not chloroform ever killed by its action on the heart. One 